\title{
VIOLÊNCIA SIMBÓLICA NA EPT - UM ESTUDO DE CASO NO CURSO TÉCNICO DE ENFERMAGEM DO INSTITUTO HUMBOLDT DE VITÓRIA/ES
}

\author{
Rafaela Gomes Bravo* \\ *rafaela_gbravo@hotmail.com \\ Instituto Federal do Espírito Santo
}

Artigo submetido em junho/2016 e aceito em novembro/2016

DOI: 10.15628/rbept.2016.4746

\section{RESUMO}

Trata-se de um estudo de caso, que contou com a participação de três turmas do curso técnico de enfermagem, do instituto humboldt, da cidade de vitória/es. O trabalho se baseia no entendimento de pierre Bourdieu, sociólogo francês, que por meio de sua teoria do habitus, afirma que a dominação sócio-econômica é majoritária e primeiramente reproduzida, pela dominação cultural. Em seus estudos voltados para a área educacional, constatou que é através da violência simbólica reproduzida no ambiente escolar, que a cultura dominante se naturaliza e se impõe como universal e superior. A partir deste entendimento, o presente trabalho teve como objetivo levantar os casos da violência simbólica no contexto pedagógico do curso técnico em enfermagem, verificar os problemas ocasionados por tal violência e identificar se os professores têm implementado ações que visem diminuir esses problemas. A pesquisa caracteriza-se como exploratória, qualitativa, se embasou em um estudo de caso, por meio de entrevistas semiestruturadas. Após a análise fenomenológica dos dados, foi possível confirmar a hipótese levantada.

PALAVRAS-CHAVE: Ensino técnico. Técnico em enfermagem. Violência simbólica. Pierre Bourdieu.

\section{SYMBOLIC VIOLENCE IN PTE - A CASE STUDY IN NURSING TECHNICIAN COURSE AT HUMBOLDT INSTITUTE IN VITÓRIA/ ES}

\begin{abstract}
This is a case study, which included the participation of three classes of nursing technical course, at Humboldt Institute, in the city of Vitória/ES. The work is based on understanding of Pierre Bourdieu, French sociologist, who through his theory of habitus, says that the socio-economic domination is the majority and first played by cultural domination. In his studies focused on the education sector, he concluded the symbolic violence held in the school environment is used to become dominant culture as natural and
\end{abstract}

impose it as universal and superior. Based on this understanding, the present study aimed to raise the cases of symbolic violence in the educational context of the technical course in nursing, check the problems caused by such violence and identify if teachers have implemented actions aimed at reducing these problems. It's a exploratory research, qualitative, that was based in the case study, through semi -structured interviews. After the phenomenological analysis of the data, it was possible to confirm the hypothesis.

KEYWORDS: Technical education. Technical nursing. Symbolic violence. Pierre Bourdieu. 


\section{INTRODUÇÃO}

Com o intuito de atender às necessidades do mercado por profissionais capacitados, o instituto humboldt oferece à comunidade o curso técnico em enfermagem. O curso tem 24 meses de duração, para as turmas de sábado e exige como requisito básico a conclusão do ensino médio. Mantém em seu currículo disciplinas práticas e teóricas e este foi o principal motivo, que levou a escolha deste curso como objeto de estudo deste trabalho. A teoria que fundamentou a pesquisa é chamada teoria do habitus, do sociólogo pierre Bourdieu.

A partir de sua própria vivência do sistema de ensino francês, Bourdieu desenvolveu uma teoria que aponta que as instituições de ensino, ainda que involuntariamente, tornaram-se uma ferramenta através da qual, disseminam as disparidades sociais. Essa expansão das diferenças sociais, de acordo com o autor, ocorre por naturalizar e impor de modo sutil a cultura dominante como superior e universal.

Segundo Bourdieu, a dominação que mais tarde se caracteriza principalmente por meio da economia, ocorre no seio das instituições de ensino, pela imposição da cultura dominante, e culmina na violência simbólica daqueles que não compreendem a dinâmica desta cultura predominante.

Diante das afirmações propostas pela teoria de Bourdieu; da análise de conceitos que dão suporte para a mesma, tais como os conceitos de habitus, capital cultural, campo, dominação simbólica e violência simbólica; e de observação pessoal de algumas turmas da escola em referência, surge a desconfiança de que a violência simbólica descrita pelo autor está realmente entranhada não só nessa, mas possivelmente em todas as instituições de ensino, motivo pelo qual é latente a necessidade de verificar caso a caso, como essa violência vitima os discentes e principalmente, como diminuir a incidência deste problema.

No presente trabalho o problema então consistiu em verificar como reduzir ou eliminar a violência simbólica no instituto humboldt. A hipótese levantada é de que por meio de ações pedagógicas diferenciadas e através do incentivo à diversidade cultural no ambiente escolar, seja possível diminuir a violência simbólica local e majorar o desempenho acadêmico dos discentes.

O objetivo maior desta pesquisa é o de reduzir a violência simbólica no curso técnico em enfermagem. Deste modo, resta notória a relevância do trabalho. A reflexão sobre a violência simbólica no ambiente escolar, leva o docente à buscar metodologias diferenciadas, que propiciem ao aluno maior assimilação e apropriação do conteúdo. O debate aqui proposto também é de suma importância para que as instituições de ensino reavaliem seu papel na sociedade e possam fazer jus à função que lhe é atribuída.

\section{REFERENCIAL TEÓRICO}

Pierre Bourdieu, importante cientista social da atualidade, é notadamente um dos que se dedicou a escrever sobre os mais diversos temas, dando grande importância a educação, até porque ele próprio, filho de camponeses, de origem humilde, se reconhecia como vítima da violência simbólica perpetuada pelo sistema educacional francês, especialmente quando passara a frequentar a école de hautes études en sciences sociales, e desenvolvera sua tese, justamente para comprovar à academia que o modelo de educação ali empregado era injusto e tinha como consequência o provável fracasso dos alunos advindos de culturas não dominantes.

A educação, na teoria de Bourdieu, perde o papel que lhe fora atribuído de instancia transformadora das sociedades e passa a ser vista como uma das principais instituições por meio da qual se mantêm e se legitimam os privilégios sociais. Trata - se, portanto, de 
uma inversão total de perspectiva. Bourdieu oferece um novo quadro teórico para a análise da educação dentro do qual os dados estatísticos acumulados a partir dos anos 50 e a crise de confiança no sistema de ensino vivenciada nos anos 60 , ganham uma nova interpretação (NOGUEIRA, 2006 p. 15)

No filme "a sociologia é um esporte de combate" (2001) o sociólogo francês afirma que o mundo vive em inércia. Ainda de acordo com Bourdieu, é através da dominação simbólica, que as coisas se mantêm da maneira que estão, ou seja, preserva-se o status quo. Levando em consideração tal premissa, e segundo a teoria do sociólogo francês, a educação do modo como é propagada, se torna instrumento dos dominantes para legitimar sua dominação. Em consonância com este posicionamento:

A cultura dominante contribui para a integração real da classe dominante (assegurando uma comunicação imediata entre todos os seus membros e distinguindo-os das outras classes); para a integração fictícia da sociedade no seu conjunto, portanto, à desmobilização (falsa consciência) das classes dominadas; para a legitimação da ordem estabelecida por meio do estabelecimento das distinções (hierarquias) e para a legitimação dessas distinções. (BOURDIEU, 2005, p. 10).

Na prática isso pode ser observado quando temos professores de formação majoritariamente propedêutica, hoje médicos, enfermeiros, advogados, psicólogos, dando aulas expositivas, utilizandose de vocabulários completamente distintos dos que os alunos costumam vivenciar; aplicando avaliações subjetivas para discentes que não conseguem formular um parágrafo coeso, claro e que faça algum sentido em suas redações; e exigindo destes alunos que assimilem as informações passadas e sejam capazes de reproduzir essas ideias em seus ambientes de trabalho. Ainda que inconscientemente, esses docentes acabam por desestimular pessoas que estavam dispostas a se especializarem e serem profissionais melhores.

"O ensino de um ofício ou, para dizer como Durkheim, de uma "arte", entendido como "prática pura sem teoria", exige uma pedagogia que não é de forma alguma a que convém ao ensino dos saberes. Como se vê bem nas sociedades sem escrita e sem escola (BOURDIEU, 2005, p. 22).

Os atos dos docentes, exemplificados acima, ilustram com perfeição a ideia de que a reprodução do poder e da violência simbólica é algo tão natural, que atinge até mesmo a utilização de nossa língua materna, afinal, os filhos dos analfabetos brasileiros, possivelmente não tiveram durante a infância contato habitual com indivíduos que falassem o português formal, provavelmente não tiveram o hábito da leitura incentivado e como consequência, esses alunos demonstram grande dificuldade de interpretação e redação, inviabilizando seus processos de aprendizagem da maneira como as instituições de ensino os ofertam. Em consonância com este entendimento, temos que:

O indivíduo que domina, por exemplo, o padrão culto da língua - aquele reconhecido como legítimo (correto) pelas instâncias às quais foi socialmente atribuído o direito e o dever de avaliar e classificar as formas de linguagem (sobretudo, a escola e os especialista das áreas de linguagem) - beneficia-se de uma série de vantagens sociais. O domínio da língua culta funciona como uma moeda (um capital) que propicia a quem o possui uma série de recompensas, seja no mercado escolar, seja no mercado de trabalho, seja até mesmo no mercado matrimonial (BOURDIEU, 1998 apud NOGUEIRA, 2006, p. 35).

A questão a ser debatida neste trabalho é a possibilidade de diminuir a incidência desse tipo de violência contra os discentes, de modo que estes sintam-se a vontade no ambiente escolar e, por se 
sentirem acolhidos, desenvolvam melhor desempenho acadêmico. O que temos hoje, é uma educação engessada que apenas reproduz o que the parece ser o correto, e evidente, conforme aduz Bourdieu na afirmação abaixo:

Ora, procede-se frequentemente como se o que pode ser reivindicado como evidence fosse evidente. $O$ que se faz em função de uma rotina cultural, a maior parte das vezes imposta e inculcada pela educação [...]. (BOURDIEU, 2005, p. 24).

Segundo a teoria do sociólogo, entretanto, esse tipo de comportamento dos docentes, ainda que de maneira inconsciente, é proposital, pois tem o poder de demonstrar o quanto seus capitais culturais são superiores e colocam o discente, geralmente advindo de famílias com capital cultural distinto, como seres inferiores, incapazes de compreender a dinâmica dominante; quando em verdade, esses apenas não convivem com essa cultura desde sua infância, como ocorrerá com os docentes, que tiveram um tempo maior para assimilar e dominar essa cultura imposta como superior.

\footnotetext{
Diante deste contexto, é necessário que se estabeleça uma maior integração entre as culturas e os povos, com base no respeito, na dignidade humana, na sensibilidade solidária, respeito às identidades culturais, à diversidade e ao outro. À educação cabe inserir em suas práticas o princípio da alteridade como forma de assegurar o sentido de pertencimento, respeito pelo outro e de participação ativa dos sujeitos (BECEVELLI, 2014, p. 185).
}

Não obstante, o enfoque dado neste trabalho ao conceito de violência simbólica, a teoria de Pierre Bourdieu só se apresenta palpável, quando consideramos outros conceitos desenvolvidos pelo francês, tais como habitus, campo, capital cultural, capital econômico, entre outros que passamos a abordar.

\subsection{SOBRE OS CONCEITOS DE BOURDIEU}

Para melhor compreensão do referencial teórico escolhido, será necessária uma sucinta explanação sobre os principais conceitos que norteiam a teoria de pierre Bourdieu. Aqui não há pretensão de explorar com riqueza de detalhes sua teoria, mas apenas de dar ao leitor as noções básicas para compreensão do trabalho. O primeiro conceito que destacaremos é a noção de habitus, já rapidamente delineada anteriormente.

De acordo com michels e volpato (2012), Bourdieu entende que:

[...] O ser humano é constituído de estruturas mentais, através das quais apreendem o mundo social. O ser humano é, em essência, o produto da interiorização das estruturas do mundo social. As representações simbólicas variam conforme a posição e conforme o habitus como sistema de esquemas de percepção e apreciação, como estruturas cognitivas avaliatórias que os seres humanos adquirem através da experiência a partir de uma posição no mundo social (BOURDIEU, 2007a apud MICHELS; VOLPATO, 2012).

Ou seja, o habitus é basicamente o elemento que permite que as pessoas possam identificar seus gostos/estilos, no meio em que vivem, de modo que possam enquadrar suas preferências individuais na sociedade. Nesse sentido, percebe-se que:

Pensar a relação entre indivíduo e sociedade com base na categoria habitus implica afirmar que o individual, o pessoal e o subjetivo são simultaneamente sociais e coletivamente orquestrados. O habitus é uma subjetividade socializada. Dessa forma, deve ser visto como um conjunto de esquemas de percepção, apropriação e ação que é 
experimentado e posto em prática, tendo em vista que as conjunturas de um campo o estimulam (BOURDIEU, 1992 apud SETTON, 2002).

Delineado o conceito de habitus para Bourdieu, necessário traçar considerações sobre o conceito de campo, que como já supramencionado, estimula a noção de habitus de cada indivíduo. Como os dois conceitos estão intimamente entrelaçados, o entendimento do significado de campo na teoria, promove uma melhor percepção sobre o conceito de habitus.

Ainda de acordo com setton (2002), na teoria em comento, tudo o que um indivíduo faz ou deixa fazer, é resultado da relação entre um habitus (eivado de subjetivismo) e as coações e estímulos produzidos por uma conjuntura, que Pierre Bourdieu nomeou de campo.

Importante observar, que campo não é apenas um espaço físico, o ambiente em que o indivíduo vivencia suas experiências. A noção de campo vai além, e abarca ainda algo metafísico, que setton bem descreve como uma conjuntura - ambiente físico, momento econômico, circunstâncias políticas, aspectos psicológicos, etc. Nesse sentido:

O conceito de campo faz parte do corpo teórico da obra de Bourdieu. Trata-se de uma noção que traduz a concepção social do autor. Campo seria um espaço de relações entre grupos com distintos posicionamentos sociais, espaço de disputa e jogo de poder. Segundo Bourdieu, a sociedade é composta por vários campos, vários espaços dotados de relativa autonomia, mas regidos por regras próprias. (SETTON, 2002, p. 64).

Nos campos, os grupos são definidos pelo capital que seus membros detêm, deste modo, o que determina e caracteriza as classes ou subculturas de classes de cada indivíduo é a soma de seus capitais culturais, sociais, econômicos e simbólicos. Para melhor compreensão desses conceitos, vejamos as colocações de silva sobre o tema:

\begin{abstract}
Capital cultural é uma expressão cunhada e utilizada por Bourdieu para analisar situações de classe na sociedade. De uma certa forma o capital cultural serve para caracterizar subculturas de classe ou de setores de classe. Com efeito, uma grande parte da obra de Bourdieu é dedicada à descrição minuciosa da cultura - num sentido amplo de gostos, estilos, valores, estruturas psicológicas, etc. - que decorre das condições de vida específicas das diferentes classes, moldando as suas características e contribuindo para distinguir, por exemplo, a burguesia tradicional da nova pequena burguesia e esta da classe trabalhadora. Entretanto, o capital cultural é mais do que uma subcultura de classe; é tido como um recurso de poder que equivale e se destaca - no duplo sentido de se separar e de ter uma relevância especial - de outros recursos, especialmente, e tendo como referência básica, os recursos econômicos. Daí o termo capital associado ao termo cultura; uma analogia ao poder e ao aspecto utilitário relacionado à posse de determinadas informações, aos gostos e atividades culturais. Além do capital cultural existiriam as outras formas básicas de capital: o capital econômico, o capital social (os contatos) e o capital simbólico (o prestígio) que juntos formam as classes sociais ou o espaço multidimensional das formas de poder (SILVA, 1995, p. 24).
\end{abstract}

Há que se destacar que o capital cultural acumulado demanda do sujeito um trabalho individual de assimilação das informações que lhe são dispostas. É um trabalho que demanda tempo e que após total assimilação, torna-se habitus. De acordo com Bourdieu, o capital cultural se apresenta de três diferentes modos: em seu estado incorporado, no objetivado e institucionalizado (Bourdieu apud nogueira, m. A.; catani, a, 2001, p. 75).

No estado incorporado, dá-se sob a forma de disposições duráveis do organismo, tendo como principais elementos constitutivos os gostos, o domínio maior ou menor da língua 
culta e as informações sobre o mundo escolar. A acumulação desta forma de capital cultural demanda que sua incorporação seja feita mediante um trabalho de inculcação e assimilação. Este trabalho exige tempo e deve ser realizado pessoalmente pelo agente. $O$ capital cultural no seu estado incorporado constitui, assim, o componente do background familiar que atua de forma mais marcante na definição do futuro escolar dos descendentes, uma vez que as referências culturais, os conhecimentos considerados apropriados e legítimos e o domínio maior ou menor da língua culta trazida de casa (herança familiar) facilitam o aprendizado dos conteúdos e dos códigos escolares, funcionando como uma ponte entre o mundo da família e o da escola. No estado objetivado, o capital cultural existe sob a forma de bens culturais, tais como esculturas, pinturas, livros, etc. Para possuir os bens econômicos na sua materialidade é necessário ter simplesmente capital econômico, o que se evidencia na compra de livros, por exemplo. Todavia, para apropriar-se simbolicamente destes bens é necessário possuir os instrumentos desta apropriação e os códigos necessários para decifrá-los, ou seja, é necessário possuir capital cultural no estado incorporado. No estado institucionalizado, o capital cultural materializa-se por meio dos diplomas escolares (CAZELLI, s, 2005, p.47-48).

De maneira grosseira e superficial, podemos dizer que a teoria de pierre Bourdieu, se traduz pela formação da identidade do agente, por meio de seus habitus - adquiridos pela acumulação de seus capitais (culturais, econômico, simbólico, etc) e por influência do campo.

Há ainda que se discorrer um pouco mais sobre o conceito de violência simbólica, o mais importante dos conceitos para a compreensão e desenvolvimento deste trabalho.

Pela teoria aqui abordada, a sociedade é um espaço permeado por disputas de poder, com fins a legitimar uma dada cultura como superior. Ou seja, na prática, é como se cada membro da sociedade lutasse para que seu próprio capital cultural fosse reconhecido como melhor que o daqueles que valorizam uma cultura distinta. Para Bourdieu, o grupo que consegue impor seu capital cultural, é aquele que dispõe de mais recursos financeiros. E a ferramenta utilizada por esse grupo para impor sua cultura seria a violência simbólica.

\begin{abstract}
A violência simbólica é uma violência, na medida em que impõe uma arbitrariedade. Tanto o conteúdo, quanto o poder e a forma de imposição são arbitrários. Porém, na prática o caráter arbitrário da cultura dominante (escolarizada) é dissimulado e é reconhecido pelos dominados como cultura legítima, universal, neutra e natural.[...] O desconhecimento dessa violência dificulta perceber a existência dela, e por essa razão tem um grande poder (MICHELS; VOLPATO, 2012, p. 8).
\end{abstract}

A escola é um dos lugares em que a violência simbólica se perpetua com maior facilidade, assim como nas igrejas ou ambientes em que há um líder impondo seus conhecimentos para os demais. Na escola, o professor via de regra representa uma autoridade, que lá está para repassar seus conhecimentos - capital cultural - para seus alunos.

O dominado não se opõe ao seu opressor, já que não se percebe como vítima deste processo, ao contrário, o oprimido considera a situação natural e inevitável. Nas escolas públicas brasileiras, ignoram-se a origem dos seus alunos, transmitindo o ensino padrão. Bourdie e Passeron explicam este processo pela ação pedagógica, que perpetua a violência simbólica através de duas dimensões arbitrárias: o conteúdo da mensagem transmitida e o poder que instaura a relação pedagógica exercido por autoritarismo (SOUZA, l; 2012, p. 27). 


\title{
2.2 A APLICAÇÃO DOS CONCEITOS DE BOURDIEU NO ÂMBITO EDUCACIONAL E POSICIONAMENTOS LIMITES À SUA TEORIA.
}

Após melhor compreensão da teoria Bourdieusiana, importante delinear a contribuição desta teoria sociológica no contexto educacional.

\begin{abstract}
A grande contribuição da sociologia da educação de Pierre Bourdieu foi, sem dúvida, a de ter fornecido as bases para um rompimento frontal com a ideologia do dom e com a noção moralmente carregada de mérito pessoal. A partir de Bourdieu, tornou-se praticamente impossível analisar as desigualdades escolares, simplesmente, como frutos das diferenças naturais entre os indivíduos (NOGUEIRA; NOGUEIRA, 2002, p.34).
\end{abstract}

Brandão também demonstra de maneira clarividente que a teoria de Pierre Bourdieu punha em cheque a escola como ambiente adequado ao convívio social e incentivador da isonomia entre os alunos, conforme se observa da afirmação que segue:

Contrariando a ideia da escola enquanto espaço social democrático e emancipador, a sociologia Bourdieusiana buscava mostrar que essa instituição legitimava as práticas sociais das classes dominantes. Longe de equiparar os escolares, fornecendo instrumentos que de forma marcante e de acordo com a necessidade, pudessem garantir o sucesso escolar, e assim, uma mudança em sua situação social, a escola reforçaria a desigualdade, uma vez que não dava possibilidades reais para que o aluno transpusesse os diversos obstáculos de ordem social e cultural (BRANDÃO, 2009, p. 101).

Apesar de todos os argumentos até aqui apresentados, conduzirem o leitor a crer que o capital cultural adquirido no seio familiar seja determinante para o desempenho escolar do indivíduo, relevante mencionar, contudo, que o capital cultural, deve ser visto como uma determinante que também pode ser socialmente construída, e consequentemente modificada:

\begin{abstract}
Não basta, para a criança, estar cercada ou envolvida de objetos culturais ou de pessoas com disposições culturais determinadas para chegar a construir competências ou habilidades culturais. Tais competências podem agir como um patrimônio cultural morto se não há efeito de socialização para colocá-las em prática (ALMEIDA; CUNHA, 2010 p. 270).
\end{abstract}

Ou seja, nem sempre um indivíduo com pais analfabetos ou que tenha pouco domínio da cultura imposta nas escolas tradicionais brasileiras, estará sujeito ao fracasso, pois pode ter em seu lar incentivo para que se empenhe na assimilação dessa nova cultura. Da mesma forma, é possível que crianças oriundas de famílias com vasto capital cultural, e já habituadas à cultura dominante, não tenham qualquer tipo de identificação com esse universo e não assimilem as informações que lhe são passadas desde seu nascimento. $O$ resultado é que o capital cultural não inculcado, não se tornará um habitus e esse indivíduo poderá apresentar dificuldades em se adequar ao ambiente escolar tradicional, que impõe o desenvolvimento e assimilação desta cultura dominante. Vejamos:

Ainda para Bourdieu (1998), o capital cultural favoreceria não só o êxito escolar, como também possibilitaria um melhor desempenho nos processos formais e informais de avaliação, pois a avaliação, segundo o autor, vai muito além da verificação da aprendizagem, mas é também responsável por um verdadeiro julgamento cultural, estético e moral dos alunos. A escola cobra o uso de um estilo elegante de falar, escrever e se portar e exige dos alunos que se mostrem interessados em relação à cultura legítima e essas exigências só podem ser plenamente atendidas por quem foi previamente (na 
família) socializado nesses mesmos valores (Bourdieu apud (ALMEIDA; CUNHA, 2010 p. 280).

Essa perspectiva levantada por Bourdieu, entretanto vai de encontro com o ideal de escola descrito por alguns teóricos, dentre eles, Nobert Elias e Saviani, que se dedicam a desvendar os problemas e sugerir melhorias à educação. Observa-se definição da função da escola por Saviani, como sendo "[...] Uma instituição cujo papel consiste na socialização do saber sistematizado" (SAVIANI, 2005, p.14). Isso significa que as instituições de ensino, têm como principal função promoverem nos discentes o despertar para o entendimento e modificação do que os cercam. Logo, é da escola o papel de assegurar a transmissão do saber, mas não de maneira mecânica e sim por meio de apropriação do capital cultural.

Na subsunção da teoria que ora se convoca, aos fatos sociais, outros autores ainda que genericamente concordem com alguns argumentos de Bourdieu, atentam-se para questões que a teoria do estudioso francês não ressaltou. Exemplo disso é a noção de habitus desenvolvida por Nobert Elias. Enquanto Bourdieu se prende às noções de habitus adquiridas pelo indivíduo majoritariamente em seu seio familiar, Elias acrescenta a esta noção o fato de que "com o passar do tempo os novos padrões de comportamento deixam de ser conscientes para tornarem-se uma segunda natureza [...] (LANDINI; PASSIANI, e. 2007, p. 06).

Ou seja, para Elias, a violência simbólica vivenciada nas instituições de ensino tornar-se-ia cada vez mais sutil, já que com o passar dos anos, os alunos advindos de culturas distintas incorporariam às suas personalidades aquela cultura tida como superior.

Outro importante limite encontrado na teoria que embasa o trabalho, diz respeito à dificuldade de aplicá-la ao caso concreto sendo fiel aos preceitos do teórico. Nesse sentido, temos que

As limitações dessa abordagem, no entanto, se revelam sempre que se busca a compreensão de casos particulares. Bourdieu nos forneceu um importante quadro macrossociológico de análise das relações entre o sistema de ensino e a estrutura social. Esse quadro precisa, no entanto, ser completado e aperfeiçoado por análises mais detalhadas. Faz-se necessário, em especial, um estudo mais minucioso dos processos concretos de constituição e utilização do habitus familiar, bem como uma análise mais fina das diferenças sociais entre famílias e contextos de escolarização (nogueira; nogueira, 2002, p.34).

Findas as considerações necessárias para o entendimento, ainda que superficial, da teoria de Bourdieu, importante apontar os procedimentos metodológicos utilizados nesse estudo de caso.

\section{PROCEDIMENTOS METODOLÓGICOS}

O presente estudo foi desenvolvido por meio de pesquisa exploratória, qualitativa, escolhida por ser a mais adequada em se tratando de pesquisas sociais em que é necessário maior envolvimento com o objeto a ser estudado. O estudo de caso foi realizado no Instituto HUmboldt localizado na cidade de vitória/es, por meio de entrevistas semiestruturadas com quatro professores e sete alunas, de três dos quatro módulos do curso técnico em enfermagem. Os entrevistados foram voluntários e as entrevistas foram gravadas e posteriormente transcritas, para facilitar a fiel reprodução das ideias externadas pelos participantes.

Além dos dados colhidos por meio de entrevistas e da análise fenomenológica destes, foi realizado também levantamento bibliográfico. A bibliografia é majoritariamente acerca da teoria que 
fundamenta o trabalho, bem como sobre teóricos que abordam o mesmo tema de maneira distinta, e discordam do posicionamento de Pierre Bourdieu em alguns aspectos.

\section{A VIOLÊNCIA SIMBÓLICA E O INSTITUTO HUMBOLDT DE VITÓRIA/ES - APRESENTAÇÃO DOS RESULTADOS}

Após a realização das entrevistas, constatou-se que o perfil dos alunos que compunham a amostragem é bastante similar, o que leva a crer que esta amostra represente a realidade ao menos de boa parte do curso. Por isso, é possível afirmar que quase a totalidade dos alunos é composta por mulheres, oriundas de famílias com poucos recursos financeiros e cujos pais tem baixo grau de instrução (nunca estudaram ou tem o ensino fundamental incompleto). Quase a totalidade das alunas entrevistadas interromperam seus estudos em algum momento da vida, por motivos diversos. A maioria por ter engravidado e/ou se casado precocemente.

Dessas alunas que se afastaram do ensino regular, grande parte não consegue retomar a rotina de estudos anterior, pois prioriza o cuidado dos filhos e sente dificuldade para se recolocar no mercado de trabalho quando o deseja. Neste ínterim tem-se que, a maioria, após anos de afastamento, termina o ensino médio por meio de supletivo e com grande defasagem nas disciplinas elementares para o bom rendimento no curso. A história de vida da maior parte das alunas entrevistadas condiz com a realidade descrita por cunha e almeida

\footnotetext{
Para as crianças desprovidas de um ambiente familiar "letrado", às vezes é difícil conceber a leitura como uma atividade extra-escolar, uma atividade não associada ao trabalho. Quando os pais não têm a prática de leitura e de escrita, que poderia desempenhar o papel de exemplo para a criança, a única solução para elas consiste então em concentrar a sua atenção e energia educativa nas práticas escolares. A esse respeito, não é incomum perceber casos de resistência entre alunos, os quais, via-de-regra, sentem-se fracassados, derrotados pela escola: muito pouco daquilo que interiorizam através da coexistência familiar lhes possibilita enfrentar as regras do jogo escolar (ter proficiência na linguagem, por exemplo, tanto escritural quanto oral (ALMEIDA; CUNHA, 2010 p. 270).
}

Dos quatro professores entrevistados, apenas a metade reconhece que seus alunos têm algum tipo de dificuldade em se adequar à cultura da escola. Essa dicotomia pode ser constatada da análise das seguintes afirmativas de professores distintos, quando questionados a respeito do desempenho dos alunos em suas disciplinas.

Professor 3 - acredita que os alunos não têm conhecimentos básicos para cursar o técnico, vejamos:

\footnotetext{
"em geral o desempenho é satisfatório, mas lógico, não é perfeito. O maior de todos os problemas é que o pessoal é muito despreparado. Apesar de todos terem o ensino médio completo, é um ensino médio "nas coxas", um ensino médio automático, não significa que eles tenham aprendido algo no ensino médio. Eles só concluíram o ensino médio e chegam aqui com diferentes graus de semianalfabetismo, ou como analfabetos funcionais."
}

Este mesmo professor acredita que como não é possível exigir que os alunos retornem à base, não é possível aplicar métodos tradicionais em suas aulas ou avaliações, conforme se verifica abaixo:

“o meu método de aula é totalmente alternativo, não tem nada de tradicional. Não posso
perder tempo tentando fazer eles entenderem coisas que não vai fazer diferença
nenhuma para eles, afinal estão fazendo um curso técnico, eu nem conseguiria prender a 
turma desse jeito. Tento trazer as coisas do cotidiano e com bom humor, de formas funcionais, para mostrar para eles como coisas que aparentemente não tem nada a ver com o que eles estão estudando pode ser fundamental. Sempre utilizo vídeos, músicas, trago tirinhas. Nunca tentei o método tradicional pois acredito que é falho, não funciona. Se tivesse funcionado eles não tinham chegado até aqui como analfabetos funcionais.[...] Quanto aos métodos avaliativos, uma das coisas que faço é não dar provas. Acho que no geral os métodos avaliativos das escolas tradicionais são falhos, a prova é um método falho. Não dá para medir conhecimento das pessoas através de provas. Mas como aqui as turmas são muito cheias, fica impossível fazer avaliações individuais. Para sair desse impasse eu mesclo trabalho de pesquisa escritos, deixando claro que não quero cópias da internet e faço exercícios durante as aulas. A pontuação é dividia em $50 \%$ nos trabalhos e 50\% em exercícios".

Por outro lado, outro docente - professor 1 - adota um posicionamento distinto, e acredita que a falha não está na defasagem, e sim na falta de interesse dos alunos:

"eu vejo que alguns, eles têm certa preguiça de ler, eles querem pronto. Eles já chegam e falam: 'professora, eu não sei'. Em faculdade eu também vejo isso. Até comentei com outros professores que isso é uma questão de geração, que hoje em dia se você quer saber o que algo significa, vai no google e você descobre. Tudo está muito fácil, então parece que eles não querem raciocinar. É mais uma questão de desinteresse."

A crença deste docente se reflete nos métodos aplicados em suas aulas e avaliações, conforme se verifica do trecho que segue:

\begin{abstract}
"com relação aos métodos de aula, são expositivas, com o uso de slides. Quanto aos métodos avaliativos, aplico provas e exercícios. A prova, meio objetiva e meio subjetiva, vale $80 \%$ dos pontos da disciplina e os trabalhos $20 \%$. [...] O desempenho nas provas é satisfatório, quando eles erram dá para ver que foi porque não estudaram. Não acho que tenham dificuldade para escrever, eles têm dificuldade talvez, de formar o raciocínio para responder.
\end{abstract}

Dos professores entrevistados, apenas um admitiu não realizar avaliações por meio de provas. Todos os outros professores avaliam os alunos com provas e distribuem outros pontos por meio de trabalhos e/ou seminários. Um dos professores também considera o comportamento do aluno, e como ele interage durante as aulas, para distribuir uma pequena parcela da pontuação total da disciplina. Isso demonstra que uma parcela dos professores, mesmo cientes de que os alunos não tiveram educação de base satisfatória, e por isso não estão preparados para o método de avaliação tradicional, insistem na aplicação de provas.

Durante as entrevistas com os alunos, contudo, foi perceptível o pavor que a maioria tem de enfrentar as provas. Essa tensão criada em torno da avaliação, fica evidente nos depoimentos e talvez tenha sido a maior representação da violência simbólica no curso, objeto de estudo, conforme é possível extrair dos depoimentos abaixo e das considerações traçadas por Brandt.

Refletindo sobre tais questões, é possível perceber que, por meio destes instrumentos avaliativos que não são formais (provas, trabalhos), mas sim comportamentais e de controle, instaura-se por parte do professor uma forma de violência simbólica (BRANDT, 2014, p. 35).

Aluna 5 - é a única com perfil diferente do relatado acima. Ciente disto, faz questão de frisar diversas vezes que é um caso a parte, já que está no terceiro ano do ensino médio e está inscrita no curso apenas para vivenciar o ambiente da área da saúde e ter certeza se deseja ingressar no curso de 
medicina. Esta aluna cursa hoje o terceiro módulo do curso e seu relato tem um peso considerável por se tratar de uma observadora que vivenciou a mesma experiência que as demais alunas, mas pode perceber as dificuldades existentes para as colegas, que para ela não são obstáculos. Vejamos seu posicionamento:

\begin{abstract}
"eu mudaria os métodos avaliativos, porque a maioria (das colegas) pararam de estudar, tem um pouco de dificuldade em pegar (a matéria), então quando fala em prova todo mundo estagna. Tem colega que nem almoça. Então assim que você fala prova, você assusta muito, entendeu? As vezes a pessoa fica tensa, sobe a pressão. Não tem nada a ver, são folhas que você tem que resolver as questões, mas infelizmente, as vezes as pessoas não estudam e a palavra prova logo assusta todo mundo. Eu acho que ao invés de prova, poderiam dar um trabalhozinho para apresentar, pois a maioria trabalha muito. [...] Há ainda a possibilidade de que elas tenham dificuldades, pois a maioria das questões é interpretação."
\end{abstract}

As observações feitas pela aluna 5, são confirmadas nas entrevistas da maioria das alunas. Essa aversão aos métodos avaliativos, fica também latente no relato da aluna 6 :

\begin{abstract}
"sempre tem provas. Eu acho péssimo. Eu prefiro trabalhos. Tem uma professora que a primeira matéria que ela deu para gente, agora ela está dando outra já, ela só deu prova. Foram duas provas. Uma ela deu de marcar " $x$ " e a outra foi discursiva, foi pior. Aí quer dizer, não tem muita opção de você ganhar pontinho. Teve gente que ficou por causa de meio ponto, ela não deu outra coisa. Ela só deu as duas provas e dividiu ali, somou, dividiu, acabou! Teve gente que precisava de um ponto, teve gente que precisava de meio, ela não deu e nem deu uma coisa extra. Entendeu? Agora dessa vez, que ela ta dando outra matéria, eu acho que ela mesmo viu a necessidade, e está dando trabalhos. Aí todo mundo gostou. E ela até perguntou para gente como a gente queria. Se queria duas provas, se queria toda semana um trabalho, para ajudar no final. [...] Mas tem outros professores que dão provas práticas, que é como se fosse oral, e é ótimo também."
\end{abstract}

O final do relato da aluna 6, demonstra que a violência simbólica não advém da avaliação por meio de provas por si só, pois os alunos não rejeitam a ideia de realizarem avaliações orais. Fica evidente então, por todo o exposto tanto por alunos quanto por professores, que a dificuldade maior dos discentes é colocar o conhecimento no papel por meio da escrita. Ou seja, é na realidade a defasagem do padrão formal da língua portuguesa e a dificuldade de interpretar textos, que coloca obstáculos para que os alunos apresentem seu conhecimento na avaliação escrita, seja ela subjetiva ou objetiva.

Apesar da prova ter sido considerada o maior retrato da violência simbólica vivenciada no curso técnico objeto do estudo, algumas atitudes dos professores durante as aulas também corroboram para o aumento dessa violência dentro do instituto. 0 relato da aluna 1 , que está há poucas semanas no curso, ainda no primeiro módulo aduz:

"eu tenho um pouquinho de dificuldade de guardar o conteúdo, as vezes não entendo muito bem os textos que são dados. Quando fiz o curso de cuidador de idosos, as vezes o professor pedia para fazer uma redaçãozinha, eu conseguia fazer, mas eu tenho um pouco de dificuldade de interpretar um texto, fazer um redação boa. [...] Eu to achando anatomia uma matéria difícil, mas algumas coisas eu to pegando. [...] A professora ta passando mais no quadro, disse que vai mandar um exercício por e-mail, para gente fazer em casa. Eu não mexo em e-mail não, mas eu tenho meus filhos que ajudam. [...] Na prática é mais fácil. A gente entende melhor." 
A aluna 1, demonstra como os professores tratam como simples e rotineiras atividades como: enviar a matéria por e-mail, pedir para que o aluno faça uma redação ou que assimile o conteúdo por meio da leitura de textos, entretanto, essas práticas corriqueiras da educação tradicional, fruto da manutenção do status quo (conforme constatado por Bourdieu), e disseminação da cultura dominante, é recebida por parte dos alunos com grande dificuldade.

Observa-se que a maior parte dos alunos do curso em tela, é composta por pessoas que tiveram educação básica deficiente, e que há muito não atuam no mercado de trabalho ou frequentam instituições de ensino, por isso, é perceptível que ferramentas como e-mails, redes sociais e afins, devem ser utilizadas de maneira comedida para não prejudicar os discentes que ainda não estão totalmente ambientados com essas tecnologias, sob pena dessas mídias se tornarem mais um meio de fomentar a violência simbólica no curso.

Ainda sobre o uso de tecnologias na educação, há de se ressaltar, que via de regra as famílias com poucos recursos financeiros, têm maior dificuldade de acesso e aquisição de aparelhos de informática. Assim, é certo que o uso corriqueiro dessas ferramentas na educação, privilegia aqueles que são oriundos de famílias com habitus da cultura dominante, e torna todos os demais, alvos da violência simbólica descrita por Bourdieu. Nesse contexto, os equipamentos eletrônicos e domínio dos mesmos, seriam considerados capital cultural.

O uso de materiais a serem fotocopiados ou impressos, também foi objeto de reclamações dos alunos entrevistados. Para a maior parte dos entrevistados, inclusive para alguns professores, seria interessante que a instituição disponibilizasse o material didático, ainda que o custo fosse repassado nas mensalidades. Com relação ao material utilizado, a última entrevistada - aluna 7, que está no segundo módulo do curso, expôs o seguinte:

\footnotetext{
"aqui devia ter uma impressora boa, porque quando a gente vai tirar (cópia), a gente paga por ela e sai horrível, sai quase tudo queimado, então a gente prefere tirar fora. Mas a maioria das pessoas não tem tempo para tirar fora, as vezes não tem dinheiro, porque quando vai tirar fora, cada folha é vinte centavos, trinta centavos. Só uma apostila dessa (e mostra a apostila) custa quarenta reais, então as vezes acontece - não tô dizendo que é sempre - mas as vezes acontece de um aluno atrasar a mensalidade, não é por relaxo, é porque você põe a passagem, as apostilas, que só uma dessa é uma matéria, e a gente tem várias. $\mathrm{E}$ ainda tem, passagem, almoço, mensalidade, então tudo isso se colocar na ponta do lápis, é custo. Ajudaria muito se na hora que a gente pagasse a mensalidade, já estivesse incluído a apostila. Porque tem uns que tiram a apostilas e outros que não tiram, por falta de condições e o aluno corre o risco de trancar, por conta das dificuldades, por não ter como acompanhar a aula. A escola tem que dar respaldo"
}

Diante das alegações da aluna 7, podemos extrair, que é necessário que tanto o professor como a instituição em si, se atentem e até que se adequem à realidade socioeconômica de seus alunos. Fica notório que não é apenas a falta de recursos financeiros que causa esse tipo de indignação na aluna, já que ela prefere até que os custos dos materiais didáticos sejam embutidos na mensalidade, entretanto ela se insurge para que a escola dê algum tipo de respaldo, talvez demonstrando, o real custo financeiro do curso, após a inclusão do valor do material nas mensalidades.

Ainda com relação ao material, um dos docentes - professor 2 - afirma que seria interessante se a instituição fornecesse um material base para os alunos, como uma apostila. Afirma também que

\footnotetext{
"acho que a instituição deveria dar mais materiais para eles (os alunos) estudarem. Deveriam fornecer uma apostila para que eles estudassem em casa e já viessem mais preparados. A instituição passa para os professores um calendário com a data das aulas de cada um, mas seria interessante se tivéssemos oportunidade de passar para eles o material da aula com antecedência, e que quando chegasse em sala de aula, nós só tivéssemos que discutir."
} 
Não obstante o clamor da maioria para que a instituição fornecesse o material das aulas prontos e antecipadamente, o que sugere que as dificuldades enfrentadas na aquisição do material (estruturais ou financeiras) também seriam um indício de violência simbólica, por minguar aqueles que não têm acesso ao material, vale observar o ponto de vista do professor 3 , avesso aos métodos tradicionais de ensino:

\footnotetext{
"eu não sei se há uma cultura enraizada na escola, acho que a escola deixa a cargo do professor a condução da disciplina. Particularmente, não acho isso correto, mas por outro lado, tomando por parâmetro todas as outras escolas aí fora, acho que é melhor dar a liberdade ao professor, pois pelo menos tem a possibilidade do professor tentar inovar. A chance de tentar padronizar, e padronizar por baixo é muito grande."
}

As considerações do professor 3, traz a tona a dificuldade de sugerir melhorias neste aspecto, já que as apostilas, quando utilizadas durante toda a disciplina, tira do professor a liberdade de inovar. Também não seria sensato nem legalmente possível, obrigar que o aluno adquirisse um material, no início do curso, como numa venda casada e mais tarde, os professores não o utilizassem por acreditar que métodos mais lúdicos são mais eficazes.

Se por um lado, ficou claro que os métodos avaliativos e a falta de sensibilidade da maioria dos professores em identificarem as dificuldades dos discentes, são causas imediatas da sempre velada violência simbólica, por outro, há que se refletir se os próprios alunos estão preparados para uma mudança significativa no ambiente escolar.

A cobrança por materiais didáticos em forma de apostila, demonstra que apesar de terem dificuldades de leitura e interpretação de texto, a cultura escolar tradicional está tão enraizada em alunos e professores, que poucos conseguem vislumbrar um sistema educacional diferente do que temos na maior parte das instituições. É justamente essa naturalidade, em achar que as dificuldades pelas quais passam é algo intrínseco ao processo de aprendizagem, que permite a manutenção do status quo e a disseminação da violência simbólica.

Apesar disso boa parte dos alunos em sua fala, foram enfáticos ao externar que preferem as disciplinas práticas, que tem dificuldades com as mais teóricas e que assimilam melhor o conteúdo quando os professores que lecionam essas disciplinas mais abstratas e conceituais se utilizam de métodos que privilegiam dinâmicas e atividades lúdicas em detrimento das aulas meramente expositivas, a aluna 6 afirma:

\footnotetext{
"os professores tentam usar os termos técnicos. Aí todo mundo fica olhando e a aula para! Mas os professores falam o que é aquilo e a gente aprende nos termos corretos, mas depois a gente volta a usar a palavra simples para identificar aquilo. Acho que depois na prática, acostuma, porque aí vê todo mundo falando... Fora os termos técnicos, tinha uma professora que falava muito baixinho, sempre os slides, depois do almoço dava aquele sono, e ela lá lendo e passando.... Mas teve uma outra professora que era da pá virada, ela era show, ninguém ficava parado, tinha muita dinâmica, ela fazia a gente participar das aulas com objetos, com brincadeiras sobre a matéria, a gente participava das aulas junto com ela, aí sim. Achavam que ela era meio louca, mas é assim que a gente registra a matéria, porque registra aquele momento."
}

Interessante notar, que apesar de muitos indícios levarem a crer que a aplicação da teoria de pierre Bourdieu pode ser facilmente comprovada nos relatos acima, é bem verdade que os limites da teoria também são identificáveis na prática. A noção de hábitus por Nobert Elias, que critica a teoria de Bourdieu ao acreditar que o indivíduo se apropria da cultura dominante, de modo que não seria eternamente vítima da violência simbólica, também passa a fazer sentido no relato da aluna 4: 


\begin{abstract}
"aprendi a gostar de ler fazendo um curso em 2014, no Senac. Quando eu comecei tava tudo muito enferrujado, pois eu tinha 10 anos afastada de qualquer tipo de conhecimento, de ensino, então tava tudo enferrujado. Teve que jogar óleo. No começo foi bem difícil. Começavam a tratar de coisas que a gente viu no ensino fundamental, no médio e eu não me lembrava mais. Agora quando eu sinto que começa a ficar difícil eu vou para a internet, porque hoje em dia a internet é uma ferramenta muito boa"
\end{abstract}

Fica evidente, que não obstante a existência de obstáculos que podem ser identificados como forma de violência simbólica, há casos em que o agente efetivamente se apropria da cultura dominante e acumula capital cultural por ter efetivamente inculcado aquele saber. Entretanto, esse posicionamento de Elias também apresenta falha ao generalizar a questão. Levando-se em consideração a amostra analisada, é seguro afirmar que apenas uma minoria consegue vencer os obstáculos impostos em forma de violência simbólica e efetivamente agregar capital cultural e incorporar um novo habitus.

\title{
5 CONSIDERAÇÕES FINAIS
}

Ao finalizar o estudo, evidenciou-se que, apesar de estarem sujeitos à imposição de cunho pedagógico e também de conteúdo, os discentes não parecem notar que se trata de uma imposição, e entendem que devem se sujeitar às normas apresentadas pelas autoridades ali presentes (personificadas na figura dos professores e coordenadores) pois é dinâmica natural do contexto escolar.

Verificou-se ainda que, não obstante, os alunos enfrentem diversos obstáculos para se adaptarem às exigências dos professores, da instituição e até do mercado de trabalho. Contudo, reconhecem os métodos utilizados para disseminar o conhecimento teórico ou prático como legítimos. Essa naturalidade comprova que apesar de se tratar de um curso técnico, e do perfil dos alunos ser bastante similar e diferente da cultura dominante; ainda assim, o curso é majoritariamente espaço de disseminação de capital cultural inerente à esta cultura dada por muitos como superior. Por meio de professores engessados nos métodos tradicionais de ensino, o conhecimento é passado de maneira que dificulta a compreensão do aluno, que por guardarem pouca intimidade com métodos alternativos, aceitam os tradicionais como neutros e universais.

Por esse e outros fatores, a violência simbólica está presente no curso técnico de enfermagem, na medida em que os alunos assimilam a ideologia dominante, sem questionar essa realidade. $O$ fato dos alunos encararem o sofrimento que lhes é imposto de maneira natural, fomenta o poder de imposição da cultura dominante, e ao longo do curso os formandos se adaptam ou sobrevivem a ela. A minoria, mais dedicada, deixa a instituição extremamente modificada, nos padrões esperados pela escola e que atende aos interesses do mercado de trabalho.

Boa parte dos alunos já atua na área da saúde, e durante as aulas, principalmente nas práticas, questionam a diferença entre o que aprenderam nos hospitais e o que é ensinado pelos professores, entretanto, a postura do professor, que se apresenta como autoridade no assunto, desestimula o debate e obriga aos discentes que se moldem à técnica utilizada pelo professor, ainda que fora da escola, o façam de maneira diversa. Assim, os saberes dominados pelos discentes, frequentemente são podados pelo sistema de ensino, enfraquecendo seus pontos de vista e os impondo que se adequem à cultura dominante.

As implicações da violência simbólica na vida dos alunos puderam ser percebidas durante as entrevistas. O nervosismo incontrolável relatado nos dias de provas; o sentimento de impotência ao falarem sobre as dificuldades que tem, em especial com a interpretação de textos e a escrita; a 
sensação de tristeza e mudança no tom de voz observada ao tratar de temas como seus históricos de vida e as possíveis relações entre esses fatores e seus desempenhos na instituição de ensino.

Esses rastros deixados pela violência simbólica, podem apontar para uma possível automatização ou mecanização do ensino, de modo que ao invés de promover a emancipação dos discentes, o curso tem apenas propiciado a parte dos alunos a oportunidade de se diplomarem, mesmo sem terem atingido o ideal de assimilação do conteúdo e de incentivo ao pensamento crítico.

Talvez, Pierre Bourdieu esteja certo ao afirmar, que não é do interesse dos detentores de poder, facilitar ou viabilizar a acumulação de capital cultural, para que assim o modelo atual de educação perpetue as desigualdades e o sentimento de inferioridade de alguns, em consonância com o que ocorre no ambiente não escolar.

Apesar disso, a impressão que se tem, é que a grande maioria dos professores, que nesta instituição tem total autonomia e consequentemente, o poder de oportunizarem uma experiência distinta aos seus alunos, sequer percebem a necessidade de implantarem mudanças radicais em seus métodos de ensino e principalmente, nos métodos avaliativos para facilitarem a apropriação do saber pelos discentes, resultando no acúmulo de capital cultural.

Nesse caso, fica latente a necessidade de conscientizar os professores sobre as dificuldades dos alunos e de debater medidas pedagógicas que permitam demonstrar a importância da educação de base, para que o aluno sinta um interesse natural de aperfeiçoar suas deficiências educacionais; mas principalmente medidas outras que permitam ao aluno assimilar o conteúdo de maneira mais eficaz, ainda que não tenha suprido suas defasagens.

Com base nessas reflexões e nas entrevistas realizadas, também se pode afirmar que professores que se dispõem a testar métodos alternativos, tanto nas aulas quanto em avaliações, têm tido melhor aceitação dos alunos, que por sua vez esclareceram que aquilo que aprendem na prática, ou numa discussão mais dinâmica em que eles próprios participam, tendem a ficar guardado na memória.

Outra constatação realizada e que muito surpreendeu, é que a cultura tradicional de ensino está tão internalizada nos alunos, que apesar de terem externado que preferem as tarefas práticas às teóricas; que não gostam de provas, especialmente discursivas, quando oportunizado pleitear algo para melhorar o curso, muitos solicitaram que a instituição elaborasse apostilas, que exigiria deles leitura, interpretação de texto e redação, justamente tudo aquilo que eles próprios relataram como desfavorável à assimilação do conteúdo.

Alguns professores também afirmaram que o material didático previamente elaborado, seria importante para melhorar o desempenho dos alunos, o que leva a crer que não refletiram com profundidade sobre as implicações do uso do material. Isso pode ser afirmado, pois dentre os três professores que gostariam de adotar as apostilas, dois, consideram que os alunos não dominam a norma culta, tem dificuldade em formular um raciocínio lógico quando precisam redigir algo, e/ou tem níveis de analfabetismo funcional ou semianalfabetismo.

Mesmo tendo resultados satisfatórios com a pesquisa, é possível constatar que para melhor compreensão das variáveis que permeiam a violência simbólica no contexto escolar, seria necessário um trabalho mais profundo e novas pesquisas, no que diz respeito às hipóteses de incidência da violência, bem como no que tange às possibilidades de diminuir essas ocorrências, pois boa parte dos alunos e até dos professores, não reconhecem as incidências rotuladas como violência simbólica como problemas estruturais do sistema escolar. 


\section{REFERÊNCIAS}

ALMEIDA, C. A; CUNHA, M. A. A. O veredicto escolar e a legitimidade das práticas culturais: uma relação bem-sucedida. Currículo sem fronteiras, UFMG, v. 10, n. 2, p. 268-283, jul/dez 2010 Disponível em: <HTTP://WWW.CURRICULOSEMFRONTEIRAS.ORG/VOL1OISS2ARTICLES/CUNHAALMEIDA.PDF> Acesso em: 10 mar 2016.

BECEVELLI, I. Educação e inclusão e a relação trabalho, cultura, ciência e tecnologia. In: Diálogos sobre a educação profissional e tecnológica - saberes, metodologias e práticas pedagógicas, Colatina, IFES, 2014.

BOURDIEU, P. O poder simbólico. Tradução Fernando Tomaz (português de portugal) - 8a ed - Rio de Janeiro, RJ: Bertrand Brasil, 2005.

Os três estados do capital cultural. In: NOGUEIRA, M. A.; CATANI, A. (orgs.) Escritos de Educação, 3a ed., Petrópolis: Vozes, 2001, p.73-79.

BRANDÃO, C.F. Intelectuais do século XX e a educação no século XXI: o que podemos aprender com eles? Marília-SP: Poiesis Editora, 2009, p. 99-119.

BRANDT, J. Violência Simbólica: Uma reflexão acerca do habitus docente. UNIVATES, SC, jun/2014. Disponível em:

https://www.univates.br/bdu/bitstream/10737/626/1/2014JoiceBrandt.pdf> Acesso em: 30 mar 2016.

CAZELLI, S Ciência, cultura, museus, jovens e escolas: quais as relações? / Tese de Doutorado de Sibele Cazelli; Orientador: Creso Franco. - Rio de Janeiro: PUC-Rio, Departamento de Educação, 2005. Disponível em: <http://www.maxwell.vrac.puc-rio.br/7122/7122_3.PDF> Acesso em: 15 mar 2016.

LANDINI,T; PASSIANI, E. Jogos habituais - sobre a noção de habitus em Pierre Bourdieu e Norbert Elias. In X Simpósio Internacional Processo Civilizador. Abr. 2007. Campinas, SP.

La sociologie est en sport de combat. A sociologia é um esporte de combate. Com Pierre Bourdieu. Realização Pierre Carles, França 2001. Produzido por C-P Productions e VF films. (139 min), color. Legendado port.

MICHELS, L. B; VOLPATO, G. Reflexões acerca da violência simbólica no contexto pedagógico do curso técnico de produção de moda do IF-SC Araranguá. VII Colóquio Ensino Médio, história e cidadania. Universidade do Estado de Santa Catarina. Florianópolis, SC. Mai-jun de 2012. Issn 2236-7977. <http://www.revistas.udesc.br/index.php/ensinomedio/article/view/2576> Acesso em: 20 out. 2015

NOGUEIRA, C. M. M. e NOGUEIRA, M. A. A sociologia da educação de Pierre Bourdieu: limites e contribuições. Educação e Sociedade. Campinas, v. 23, n. 78, p. 15-35, abr. 2002. Disponível em: 
<http://www.gestaoescolar.diaadia.pr.gov.br/arquivos/File/pdf/sociologia_educacao_bordieau.p df> Acesso em: 17 mar 2016.

. Bourdieu \& a Educação. Belo Horizonte: Autêntica, 2006.

SAVIANI, D. A PEDAGOGIA HISTÓRICO-CRÍTICA: PRIMEIRAS APROXIMAÇÕES. 9a ED. CAMPINAS: AUTORES ASSOCIADOS, 2005.

SETTON, M. A teoria do Habitus em Pierre Bourdieu: uma leitura contemporânea. In revista brasileira de educação. Mai/jun/jul/ago, 2002. № 20. Disponível em: <http://www.scielo.br/pdf/rbedu/n20/n20a05> Acesso em: 18 fev. 2016.

SILVA, G. O. V. Capital Cultural, Classe e Gênero em Bourdieu. In INFORMARE - Cadernos do Programa de Pós-Graduação em Ciência da Informação. ECOIUFRJ - IBICT/CNPq. v.I, n.2, p.24-36, jul./dez. 1995.

SOUZA, L. P. A violência simbólica na escola: contribuições de sociólogos franceses ao fenômeno da violência escolar brasileira. In revista labor, n. 7, v. 1, ISSN: 19835000, p. 20-34, 2012. Disponível em: <http://www.revistalabor.ufc.br/Artigo/volume7/2_A_violencia_simbolica_na_escola__Liliane_Pereira.pdf> Acesso em: 17 mar 2016. Acesso em: 17 mar 2016. 